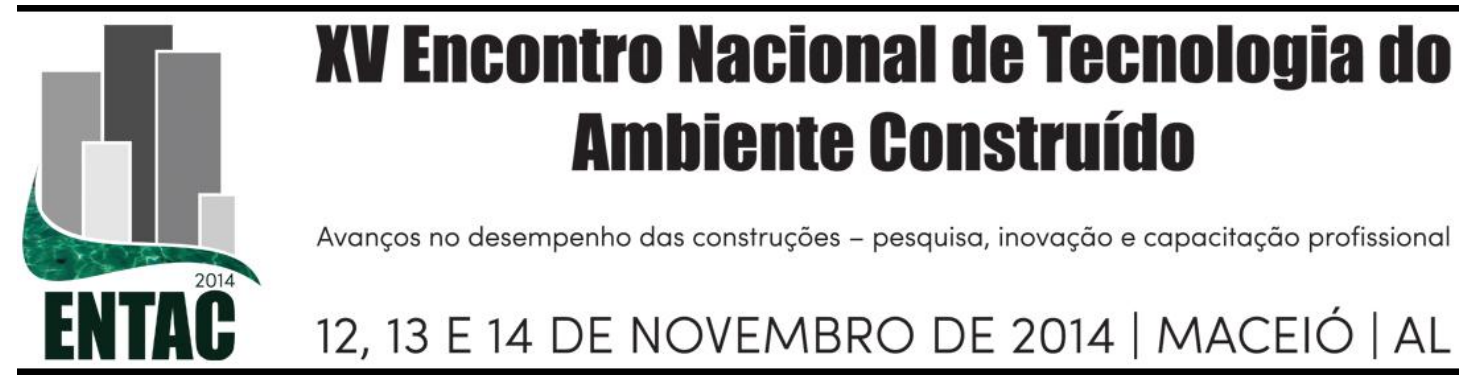

\title{
CONFORTO LUMÍNICO NO AMBIENTE ESCOLAR: NÍVEIS DE ILUMINÂNCIA EM ESCOLAS PÚBLICAS DE ÁLVARES MACHADO - SP
}

\author{
AGUIAR, Victor (1); BUENO-BARTHOLOMEI, Carolina Lotufo (2) \\ (1) FCT/UNESP, e-mail: victormarq90@gmail.com (2) FCT/UNESP, e-mail: \\ carolinalotufo@fct.unesp.br
}

\begin{abstract}
RESUMO
Este trabalho verificou em Álvares Machado, município vizinho a Presidente Prudente, no Estado de São Paulo, se os níveis de iluminância natural e artificial de duas edificações escolares públicas, com faixas etárias diferentes, atendiam o recomendado na ABNT NBR ISO/CIE 8995-1 (2013): Iluminação de Ambientes de Trabalho - Parte 1: Interior. Na referida norma são recomendados para as salas de aula o valor de 300 lux e nas as lousas 500 lux. Em cada escola foram selecionadas duas salas de aula, com funcionamento manhã e tarde; posteriormente ocorreram as medições em duas estações, inverno e verão. Segundo constatado, os valores não atendem o proposto em alguns dos períodos, sobretudo nas áreas afastadas das aberturas, inclusive com o complemento da iluminação artificial. No entanto, também foram coletados valores que excedem o aconselhado. Este trabalho foi financiado pela Fundação de Amparo à Pesquisa do Estado de São Paulo (FAPESP), modalidade Iniciação Científica, e realizado entre os meses de março de 2012 a janeiro de 2013.
\end{abstract}

Palavras-chave: Iluminação, Conforto Lumínico, Ambiente Escolar.

\begin{abstract}
This study examined in Alvares Machado, neighboring city of Presidente Prudente, known as the capital of West Paulista, in São Paulo, if the levels of natural and artificial illuminance of two public school buildings, with different age groups attended the recommended in ABNT NBR ISO/CIE 8995-1 (2013): Lighting of Work Places - Part 1: Indoor. The Standard advises classrooms the value of 300 lux and 500 lux slates. In each school two classrooms, working with morning and afternoon were selected subsequently occurred to measurements in two seasons, winter and summer. According verified, the values do not meet the proposed, in some periods, especially in the outlying areas of the openings, including the complement of artificial lighting. But, also collect amounts exceeding the recommended. This work was funded by the Foundation for Research Support of the State of Sao Paulo (FAPESP), modality Scientific Initiation, and conducted between the months of March 2012 to January 2013.
\end{abstract}

Keywords: Lighting, Comfort Luminic, School Environment.

\section{INTRODUÇÃO}

O correto emprego da iluminação natural, aponta Pereira (2006), requer uma análise detalhada da função de cada ambiente e a compreensão de seu comportamento, garantindo o conforto lumínico dos usuários e a redução do consumo de energia. Porém, observamos em algumas edificações escolares a falta de estratégias ao seu aproveitamento, tampouco a consideração das características do clima e a implantação 
no terreno, o que exige o complemento com a iluminação artificial, ainda durante o dia (KOWALTOWSKI et al., 1999; KRÜGER et al., 2004).

No cálculo da iluminação artificial, para garantir a realização das atividades, Vianna e Gonçalves (2007) destacam alguns fatores a serem considerados, como o tipo de iluminação, as especificações da lâmpada, o período de manutenção das luminárias, as reflexões nas paredes e no teto, a depreciação do fluxo luminoso com o tempo e as dimensões relativas entre comprimento, largura e altura do ambiente.

Nas salas de aula sabemos que a tarefa visual inclui desde a visão à distância, como ler na lousa, até as próximas, ler e escrever. Infelizmente, quando os níveis de iluminância são insatisfatórios acarretam danos à saúde, causando desde um ardor nos olhos até a fotofobia, refletindo no desempenho escolar. Conforme Kowaltowski et al. (1999) outras condicionantes ambientais que influenciam o desempenho, inclusive $o$ comportamento social, são: as temperaturas elevadas, o ruído exagerado, a densidade excessiva nas salas e o mobiliário não adaptado às faixas etárias.

Percebemos que algumas variáveis na iluminação, natural ou artificial, são fundamentais a serem consideradas e se negligenciadas conferem um ambiente escolar que dificilmente estimula a aprendizagem. Aliadas às preocupações com o conforto e a sustentabilidade, novas propostas buscam apresentar modelos distantes das salas com carteiras dispostas em fileiras, apostando no ensino em grupo, integração do interior com o exterior e possibilidades de modificação do mobiliário. $\mathrm{O}$ que solicita do arquiteto contribuições às questões do cotidiano, afirma Kowaltowski (2011), visto que a partir do desenvolvimento do projeto de arquitetura, constitui-se o espaço físico escolar, que deve expressar os aspectos de uma comunidade.

A qualidade do ensino, portanto, não é resultado somente da capacitação dos professores, mas das características do ambiente, que carece proporcionar espaços agradáveis, assegurando os índices de conforto, e condizentes com as atuais modificações do ensino.

\section{MATERIAL E MÉTODO}

As etapas de desenvolvimento do trabalho foram divididas em quatro:

1. Revisão da literatura;

2. Identificação das características projetuais das escolas;

3. Caracterização das salas de aula avaliadas;

4. Medição e análise dos dados;

\subsection{Revisão da literatura}

Foram realizadas consultas em livros, teses de mestrado e doutorado e anais de congressos, buscando fundamentar a metodologia de medição, o emprego da iluminação natural e artificial e os atuais parâmetros em projetos de escolas.

\subsection{Identificação das características projetuais das escolas}

As duas edificações avaliadas se localizam em Álvares Machado - SP, na área central. A cidade, com população de 23.513 habitantes (IBGE, 2010), possui oito escolas, sendo quatro de responsabilidade do município, com ensino infantil e fundamental, e uma do estado, de ensino médio, além de três particulares. Em 2010, estavam matriculados 6.012 alunos, dados do Sistema Estadual de Análise de Dados (SEADE). Na 
classificação de Köppen seu clima é Aw, tropical com inverno seco, prevalecendo os meses mais quentes em janeiro e fevereiro.

A Escola Municipal de Ensino Infantil e Fundamental, faixa etária de 6 a 14 anos, está implantada no Eixo Nordeste-Sudoeste (Figura 1.a). Sua área construída é de $1.769 \mathrm{~m}^{2} \mathrm{e}$ a do terreno de $6.315,75 \mathrm{~m}^{2}$. Nas elevações dos blocos não foram previstos elementos externos de proteção, apenas cortinas e persianas (Figuras 1.b e 1.c).

Figura 1 - (a.) Cronologia da ampliação da Escola Municipal de Ensino Infantil e Fundamental; (b.) Elevação Nordeste, em destaque a Sala do $8^{\circ}$ ano A e $1^{\circ}$ ano B (julho); (c.) Elevação Sudoeste, em destaque a Sala do $9^{\circ}$ ano $\mathrm{C}$ e $6^{\circ}$ ano $\mathrm{A}$ (dezembro).

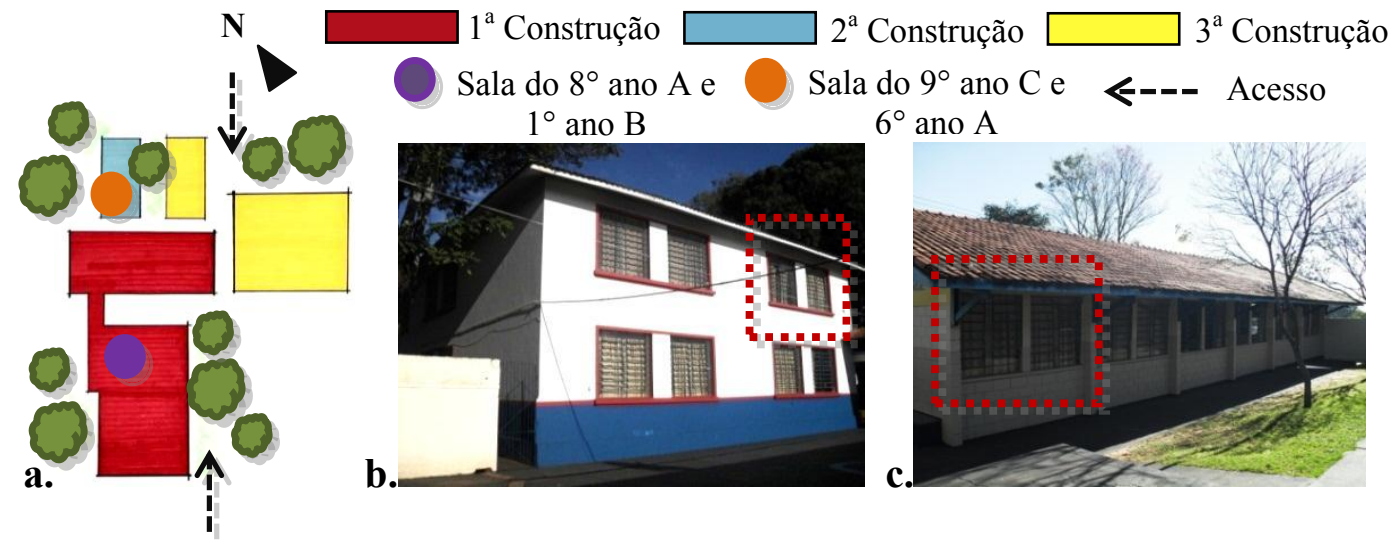

Fonte: Autores (2012)

Em razão de ser uma das primeiras escolas da cidade, no decorrer dos anos houve ampliações, resultando em salas de aula com diferentes características, em relação a materiais construtivos, dimensões, altura do pé-direito, esquadrias, revestimentos e número e distribuição de luminárias. No que se refere à diferença de materiais construtivos, as salas do bloco azul, com dimensões de $6,80 \mathrm{~m} \times 6,80 \mathrm{~m}$, foram construídas com blocos de concreto e possuem uma viga no centro, enquanto as do bloco amarelo, com 7,25 $\mathrm{m} \mathrm{x} \mathrm{7,25} \mathrm{m,} \mathrm{construídas} \mathrm{no} \mathrm{mesmo} \mathrm{ano} \mathrm{da} \mathrm{quadra}$ poliesportiva, mantiveram o padrão em alvenaria do bloco vermelho, e possuem $5,20 \mathrm{~m}$ x 8,00 m. As salas tem capacidade para 29 alunos.

Figura 2 - (a.) Cronologia da ampliação da Escola Estadual Profa. Angélica de Oliveira; (b.) Elevação Sudeste, em destaque a Sala do $3^{\circ} \mathrm{C}$ e $1^{\circ}$ ano $\mathrm{C}$ (junho); (c.) Elevação Noroeste, em destaque a Sala do $1^{\circ}$ ano $A, 1^{\circ}$ ano $B$ e $1^{\circ}$ ano $F$ (novembro).

$\square 1^{\mathrm{a}}$ Construção

Sala do $3^{\circ} \mathrm{C}$ e $1^{\circ}$ ano $\mathrm{C}$

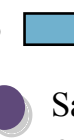

Sala $2^{\circ}$ ano $\mathrm{C}, 1^{\circ}$ ano $\mathrm{E}$ e $3^{\circ}$ ano $\mathrm{F}$
Ł-ュ-Acesso

$1^{\circ}$ ano $\mathrm{A}, 1^{\circ}$ ano $\mathrm{B}$ e $1^{\circ}$ ano $\mathrm{F}$

a.
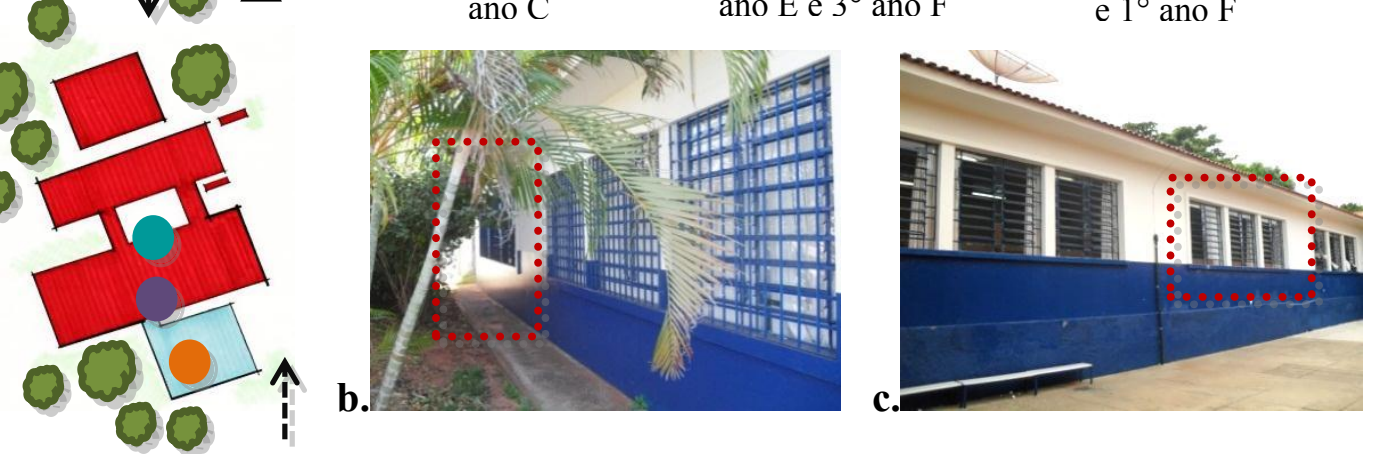

Fonte: Autores (2012) 
A Escola Estadual Profa. Angélica de Oliveira, área construída de 2.360,30 $\mathrm{m}^{2}$ e do terreno de 8.200,60 $\mathrm{m}^{2}$, está implantada no Eixo Noroeste-Sudeste (Figura 2.a) e atende alunos com faixa etária entre 15 a 17 anos, no período da manhã, tarde e noite.Também não foram instalados elementos externos de proteção nas elevações, apenas cortinas e persianas (Figuras 2.b e 2.c). Foi ampliada a partir da construção de um bloco com cinco salas, que possuem características semelhantes ao primeiro, quanto à dimensão, esquadrias e revestimentos. Todas as salas de aula apresentam as dimensões de $6,00 \mathrm{~m} \mathrm{x}$ 9,00 m, pé-direito de 3,40 m, e comportam 40 alunos.

\subsection{Caracterização das salas de aula avaliadas}

Na Escola Municipal de Ensino Infantil e Fundamental, a Sala do $8^{\circ}$ ano A e $1^{\circ}$ ano B, faixa etária 13 e 6 anos respectivamente, recebe a incidência da radiação na elevação Nordeste, enquanto a Sala do $9^{\circ}$ ano $\mathrm{C}$ e $6^{\circ}$ ano A, faixa etária de 14 e 11 anos, na Sudoeste. As salas dispõem de seis luminárias com duas lâmpadas fluorescentes cada.

A Sala do $8^{\circ}$ ano A e $1^{\circ}$ ano $\mathrm{B}$ apresenta as paredes com pintura branca e amarela dividida por uma faixa em madeira na cor azul. As duas aberturas basculantes, com vidro liso, apresentam a dimensão de $2,30 \mathrm{~m}$ x 2,00 $\mathrm{m}$ e peitoril de $1,00 \mathrm{~m}$ de altura. $\mathrm{O}$ beiral do telhado possui $0,50 \mathrm{~m}$. A instalação de interruptores permite o acionamento tanto das luminárias quanto dos ventiladores. Na medição de verão (dezembro) uma luminária estava com duas lâmpadas queimadas (Figura 3.a).

Figura 3 - (a.) Layout do posicionamento das luminárias da Sala do $8^{\circ}$ ano A e $1^{\circ}$ ano B; (b.) Layout do posicionamento das luminárias da Sala do $9^{\circ}$ ano $\mathrm{C}$ e $6^{\circ}$ ano A; (c.) Sala do $8^{\circ}$ ano A e $1^{\circ}$ ano B no período da manhã durante o inverno (julho), condição de iluminação natural.
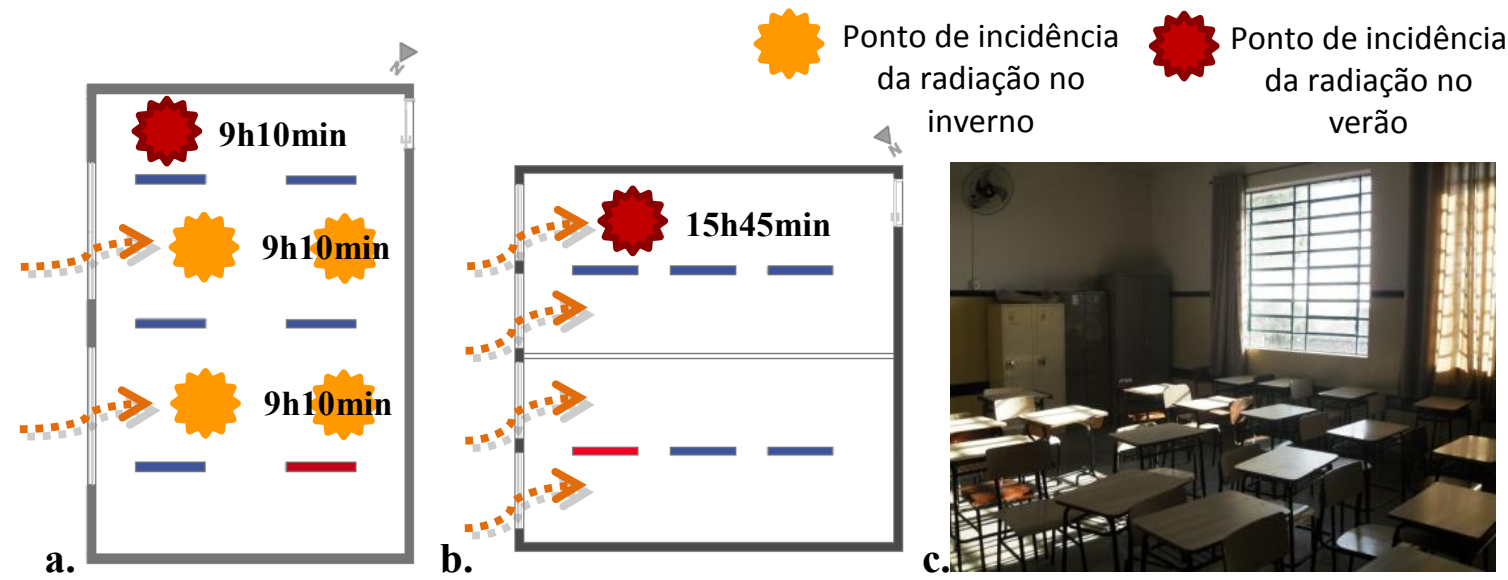
da radiação no inverno verão

Fonte: Autores (2012)

Nas paredes da Sala do $9^{\circ}$ ano $\mathrm{C}$ e $6^{\circ}$ ano A foram utilizadas duas cores, amarelo e ocre. As aberturas, quatro basculantes com vidro liso, possuem a dimensão de 2,00 $\mathrm{m} \mathrm{x} \mathrm{1,60}$ $\mathrm{m}$ e o peitoril de $1,30 \mathrm{~m}$ de altura. O beiral do telhado é de 1,20 m. Não apresenta no interior interruptores para o acionamento das luminárias e ventiladores. Esses localizam-se no quadro geral instalado no pátio, exigindo o controle de um funcionário. No inverno (julho) uma lâmpada estava inativa (Figura 3.b).

A incidência da radiação na Sala do $1^{\circ}$ ano $\mathrm{A}, 1^{\circ}$ ano $\mathrm{B}$ e $1^{\circ}$ ano $\mathrm{F}$, faixa etária de 15 anos, na Escola Estadual Profa. Angélica de Oliveira, ocorre na elevação Noroeste e na Sala do $3^{\circ}$ ano $\mathrm{C}$ e $1^{\circ}$ ano C, faixas etárias de 17 e 15 anos, na Sudeste. Na medição de 
verão (novembro), como a Sala do $3^{\circ}$ ano $\mathrm{C}$ e $1^{\circ}$ ano $\mathrm{C}$ foi transformada em depósito em razão de desistências e transferências para o período da noite, realizou-se $\mathrm{o}$ levantamento na Sala do $2^{\circ}$ ano $\mathrm{C}, 1^{\circ}$ ano $\mathrm{E}$ e $3^{\circ}$ ano $\mathrm{F}$, faixas etárias de 16,15 e 17 anos respectivamente, com incidência semelhante.

Figura 4 - (a.) Layout do posicionamento das luminárias da Sala do $3^{\circ}$ ano $\mathrm{C}$ e $1^{\circ}$ ano C; (b.) Layout do posicionamento das luminárias da Sala do $1^{\circ}$ ano $\mathrm{A}, 1^{\circ}$ ano

$\mathrm{B}$ e $1^{\circ}$ ano $\mathrm{F}$; (c.) Sala do $1^{\circ}$ ano $\mathrm{A}, 1^{\circ}$ ano $\mathrm{B}$ e $1^{\circ}$ ano $\mathrm{F}$ no período da manhã durante o verão (novembro), condição de iluminação natural.

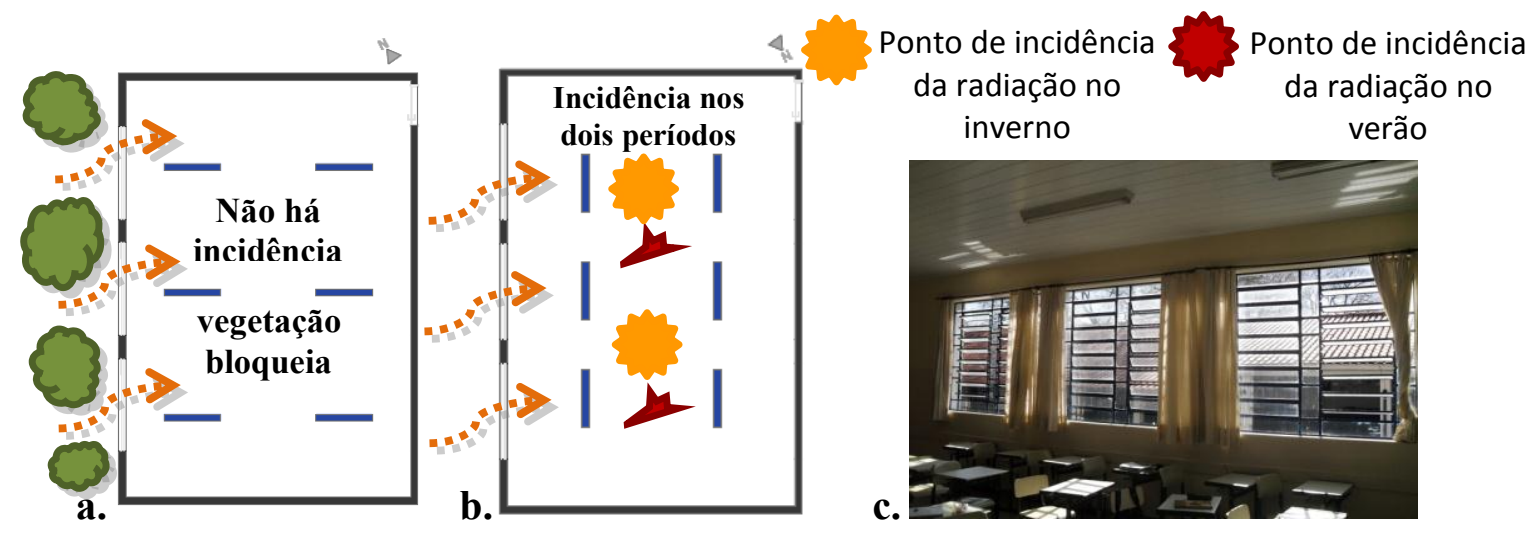

Fonte: Autores (2012)

As três salas apresentam paredes na cor ocre e três aberturas basculantes, com vidro liso, com a dimensão de $2,00 \mathrm{~m} \times 1,50 \mathrm{~m}$, peitoril de $1,30 \mathrm{~m}$ e beiral de $0,70 \mathrm{~m}$. Não possuem interruptores no interior para acionar as seis luminárias, com duas lâmpadas fluorescentes, e os ventiladores. Esses sistemas de acionamento estão localizados em um quadro geral na secretaria e o controle é realizado por uma funcionária. Durante a reforma na Sala do $1^{\circ}$ ano $\mathrm{A}, 1^{\circ}$ ano $\mathrm{B}$ e $1^{\circ}$ ano $\mathrm{F}$ e na do $2^{\circ}$ ano $\mathrm{C}, 1^{\circ}$ ano $\mathrm{E}$ e $3^{\circ}$ ano $\mathrm{F}$, o forro em madeira foi substituído por PVC, do mesmo modo o revestimento de tacos por granilite. Nas duas estações todas as luminárias estavam em funcionamento (Figuras 4.a e 4.b).

\subsection{Medição e análise dos dados}

Antes da realização das medições foi elaborada a malha do percurso para a verificação dos níveis de iluminância na sala e na lousa. Foram adotados vinte e cinco (25) pontos, para que houvesse a melhor divisão da malha em todas as salas avaliadas. Desse modo, foram coletados em 25 pontos no piso e 3 pontos na lousa, com o luxímetro, o nível de iluminância nas estações de inverno (junho-julho) e verão (novembro-dezembro), com a luz acesa e apagada, cortinas abertas e fechadas. Ao todo foram realizadas quatro medições nas escolas, duas em cada sala, em dois horários, no intervalo das aulas, no período da manhã, $09 \mathrm{~h} 10 \mathrm{~min}$ à $09 \mathrm{~h} 40 \mathrm{~min}$, e à tarde, $14 \mathrm{~h} 40 \mathrm{~min}$ às $15 \mathrm{~h} 10 \mathrm{~min}$, e $15 \mathrm{~h} 10 \mathrm{~min}$ às $15 \mathrm{~h} 40 \mathrm{~min}$, com o objetivo de reduzir a interferência dos alunos. Durante as medições foram entregues aos alunos questionários com a finalidade de avaliar se a percepção destes coincidia com os dados coletados. Posteriormente à medição, os dados foram tabulados e os gráficos e curvas isolux elaborados, permitindo verificar a diferença do nível de iluminância entre as estações e os horários. 
Embora tenham sido realizadas as medições em quatro condições distintas, são apresentados neste artigo os resultados com as luzes acesas e apagadas, estando as cortinas abertas, uma vez que representam a situação usual das salas.

\subsection{Escola Municipal de Ensino Infantil e Fundamental}

Os valores dos níveis de iluminância na Sala do $8^{\circ}$ ano $\mathrm{A}$ e $1^{\circ}$ ano $\mathrm{B}$ da Escola Municipal de Ensino Infantil e Fundamental, no período da manhã, com luzes acesas, na área próxima das aberturas permanecem acima de 2.000 lux durante o inverno, enquanto no verão, estão acima de 2.400 lux.

Figura 5 - Curvas Isolux da Sala do $8^{\circ}$ ano A e $1^{\circ}$ ano B durante o inverno (a.) e verão (b.) na condição de iluminação artificial no período da manhã - sem escala.

a.
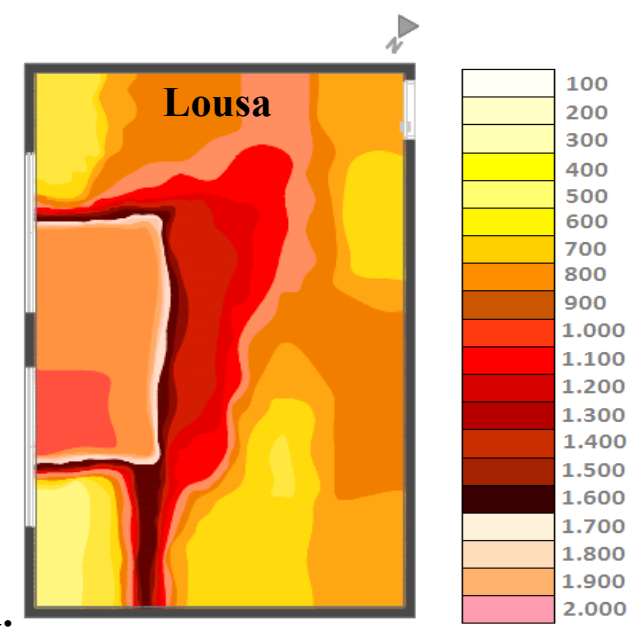

Fonte: Autores (2012) b.

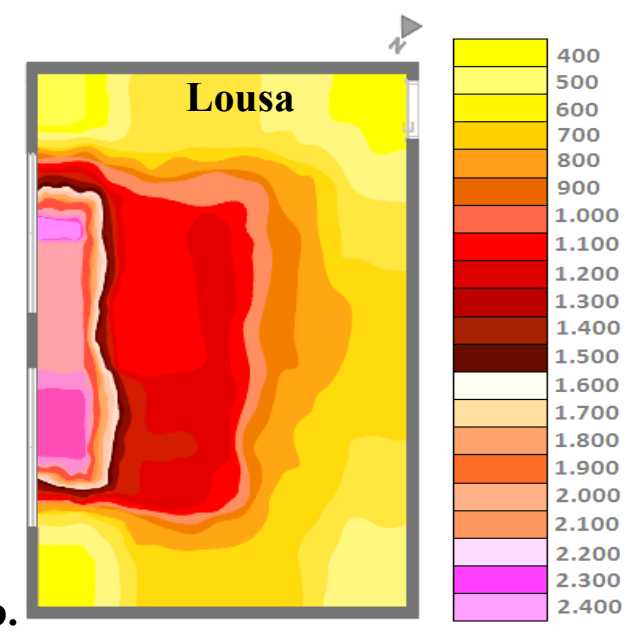

Observa-se, a partir das curvas isolux, que nas duas estações todos os valores obtidos superam o recomendado na ABNT NBR ISO/CIE 8995-1 (2013) e a diferença dos níveis de iluminância dos pontos próximos das aberturas em relação aos da parede oposta, em alguns casos, foi superior a 1.000 lux (Figuras 5.a e 5.b). No inverno foi verificada a maior média dos níveis de iluminância medidos (1.198 lux), de modo que a diferença entre as estações foi de 194 lux.

No período da tarde na mesma sala, com as luzes apagadas, os valores dos níveis de iluminância nos pontos próximos das aberturas estavam acima de 300 lux no inverno, e no centro da sala não excederam 262 lux (Figura 6.a). Situação distinta do verão, no qual os valores obtidos próximos das aberturas foram superiores a 2.000 lux e no centro da sala superiores a 634 lux (Figura 6.b). A maior média foi constatada no verão (583,38 lux), sendo a diferença entre as estações de 340,44 lux. 
Figura 6 - Gráficos da Sala do $8^{\circ}$ ano A e $1^{\circ}$ ano B durante o inverno (a.) e verão (b.) na condição de iluminação natural no período da tarde.
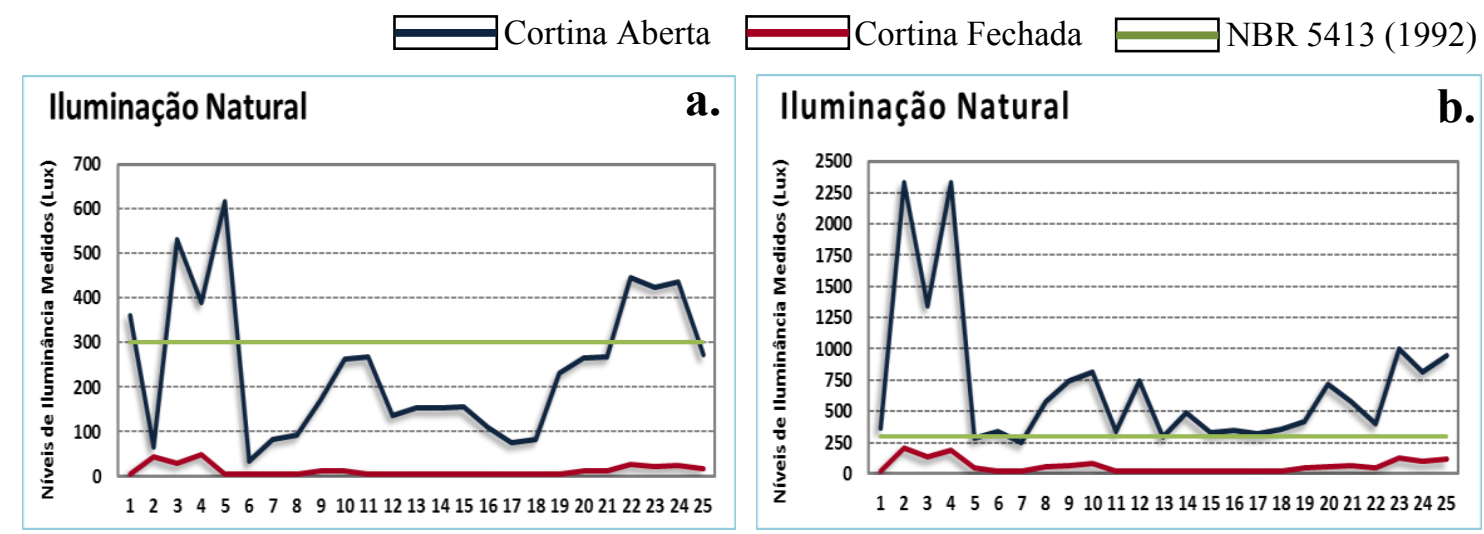

a.

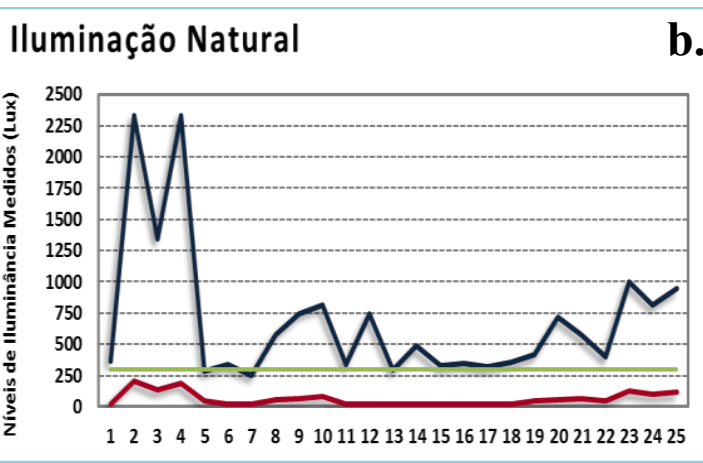

Fonte: Autores (2012)

$\mathrm{Na}$ Sala do $9^{\circ}$ ano $\mathrm{C}$ e $6^{\circ}$ ano A, período da tarde, a distribuição foi homogênea, devido à maioria dos valores estarem acima de 300 lux (Figura 7.a). No verão houve um acréscimo de iluminância em alguns pontos na área das aberturas, de modo que três foram superiores ao recomendado (Figura 7.b), consequentemente foi obtida a maior média, 404,40 lux, sendo a diferença entre as estações de 70,88 lux. Se na condição de luz acesa a maioria dos valores se enquadra, com a luz apagada, no inverno, apenas dois, próximos das aberturas, atendem o mínimo (200 lux). No verão somente um, com valor de 300 lux.

Figura 7 - Curvas Isolux da Sala do $9^{\circ}$ ano $\mathrm{C}$ e $6^{\circ}$ ano A durante o inverno (a.) e verão (b.) na condição de iluminação artificial no período da tarde - sem escala.

a.

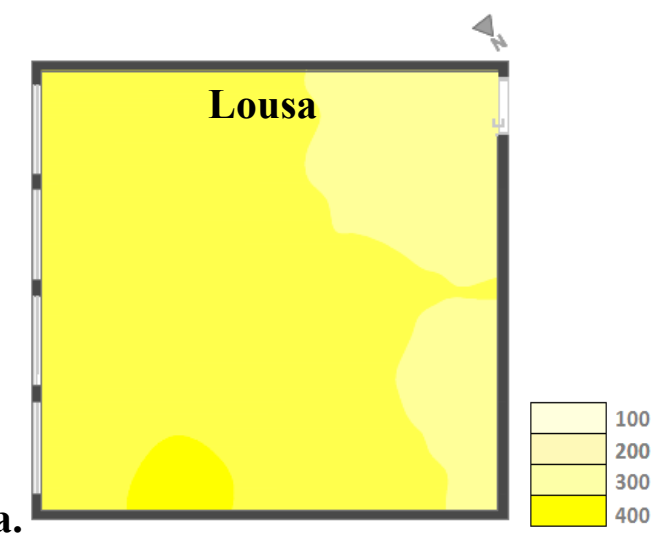

Fonte: Autores (2012)

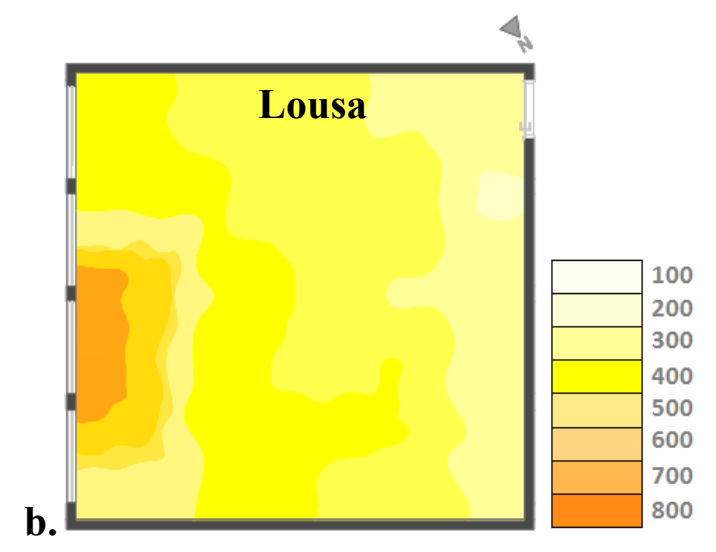

b.

\subsection{Escola Estadual Profa. Angélica de Oliveira}

Na Escola Estadual Profa. Angélica de Oliveira ainda que as medições não tenham ocorrido na mesma sala nos períodos de verão e inverno, apresentam semelhante incidência da radiação. No inverno, com a luz acesa, na Sala do $3^{\circ}$ ano $\mathrm{C}$ e $1^{\circ}$ ano $\mathrm{C}$, período da manhã, próximo das aberturas três pontos apresentavam valores de iluminância abaixo do recomendado. Na Sala do $2^{\circ}$ ano $\mathrm{C}, 1^{\circ}$ Ano $\mathrm{E}$ e $3^{\circ}$ ano $\mathrm{F}$, no verão, nenhum ponto se enquadrou dentro dos limites recomendados. Comparadas as médias das iluminâncias, verificou-se a maior no verão (330,44 lux), de modo que a diferença entre as estações foi de 39,49 lux. A situação agrava-se nas duas salas com a 
luz apagada, uma vez que nenhum valor alcança 300 lux (Figuras 8.a e 8.b). A maior média registrada foi no verão (137,04 lux) sendo a diferença entre as estações de 7,24 lux.

Figura 8 - Gráficos da Sala do $3^{\circ}$ ano $\mathrm{C}$ e $1^{\circ}$ ano $\mathrm{C}$ durante o inverno (a.) e Sala do $2^{\circ}$ ano $\mathrm{C}, 1^{\circ}$ ano $\mathrm{E}$ e $3^{\circ}$ ano $\mathrm{F}$ no verão (b.) na condição de iluminação natural no período da manhã.
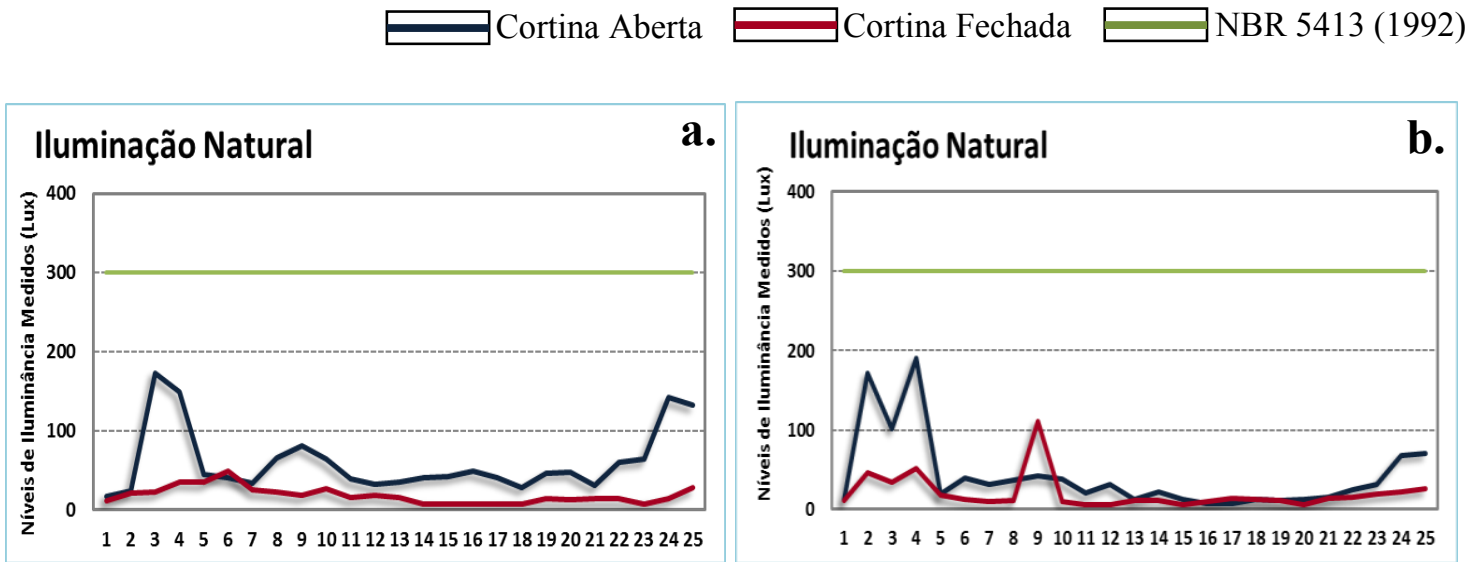

a.

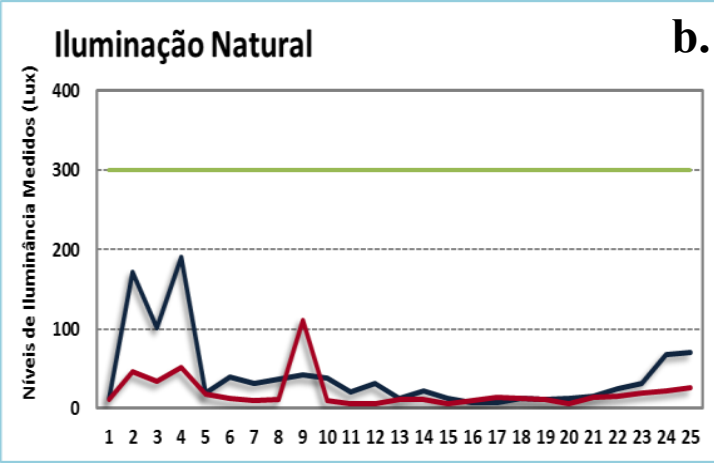

Fonte: Autores (2012)

No inverno no período da tarde, com a luz apagada, na Sala do $3^{\circ}$ ano $\mathrm{C}$ e $1^{\circ}$ ano $\mathrm{C}$ verificou-se novamente que a maioria dos valores foi inferior a $100 \mathrm{lux}$. Na área próxima à lousa e no fundo da sala estavam pouco acima de 28 lux. O menor valor registrado foi 17 lux. Observou-se no verão, na Sala do $2^{\circ}$ ano $\mathrm{C}, 1^{\circ}$ Ano $\mathrm{E}$ e $3^{\circ}$ ano $\mathrm{F}$ que três pontos apresentaram valores acima de 100 lux, todos na proximidade das aberturas. A maior média foi verificada no inverno (60,28 lux), de modo que a diferença entre as estações foi de 14,84 lux.

Figura 9 - Curvas Isolux da Sala do $1^{\circ}$ Ano A, $1^{\circ}$ Ano B e $1^{\circ}$ Ano F durante o inverno (a.) e verão (b.) na condição de iluminação artificial no período da manhã - sem escala.
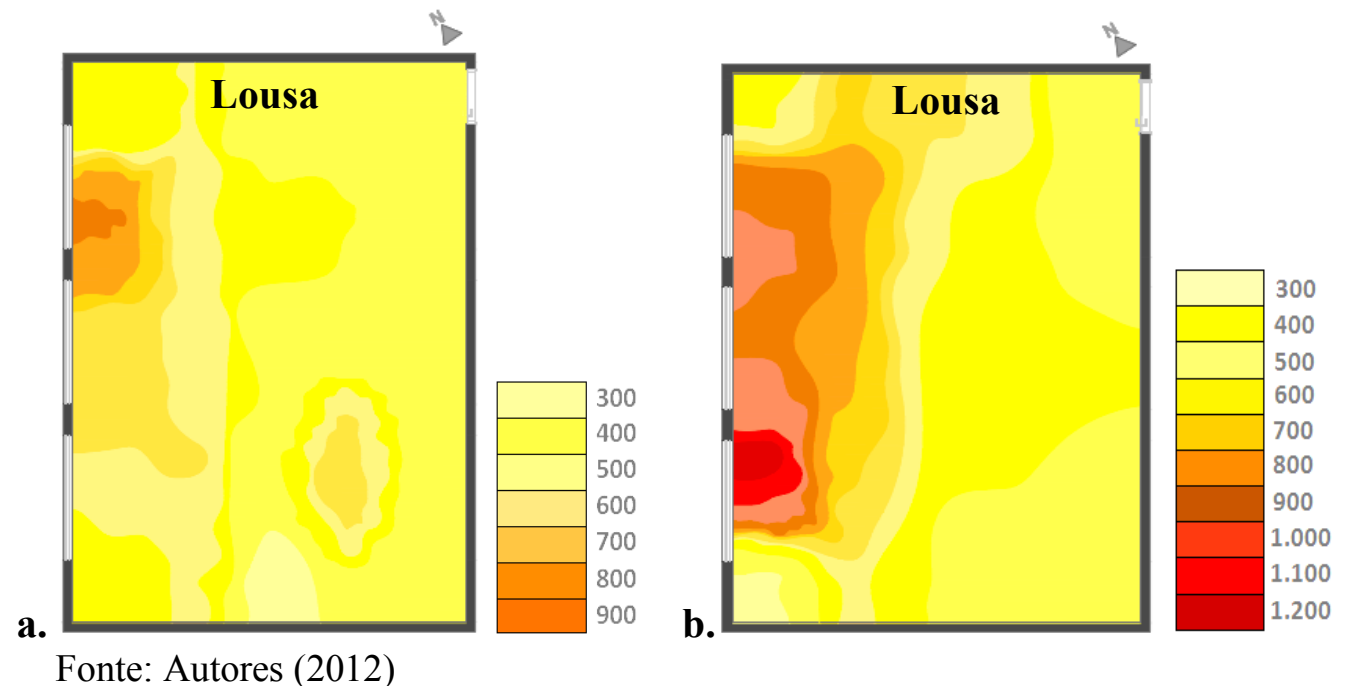

Os valores das iluminâncias dos pontos próximos das aberturas no inverno, com a luz acesa no período da manhã, na Sala $1^{\circ}$ Ano A, $1^{\circ}$ Ano B e $1^{\circ}$ Ano F estavam acima de 
439 lux (Figura 9.a). No verão, constatou-se um acréscimo nos valores das iluminâncias em pontos próximos das aberturas, ultrapassando 1.200 lux (Figura 9.b). Registrou-se a maior média no verão (554,40 lux), sendo a diferença de 81,88 lux entre as estações. Com a luz apagada, no inverno, os valores obtidos próximo das aberturas também permaneceram acima de 400 lux. Enquanto no verão, foram próximo de 1.000 lux, porém um ponto não atendeu os 300 lux, devido ao trecho de alvenaria. Os pontos distantes das aberturas no inverno estavam abaixo do mínimo necessário. Durante o inverno foi coletada a maior média $(255,20$ lux $)$, sendo a diferença entre as estações de 194,92 lux.

Figura 10 - Curvas Isolux da Sala do $1^{\circ}$ Ano A, $1^{\circ}$ Ano B e $1^{\circ}$ Ano F durante o inverno (a.) e verão (b.) na condição de iluminação artificial no período da tarde sem escala.

a.

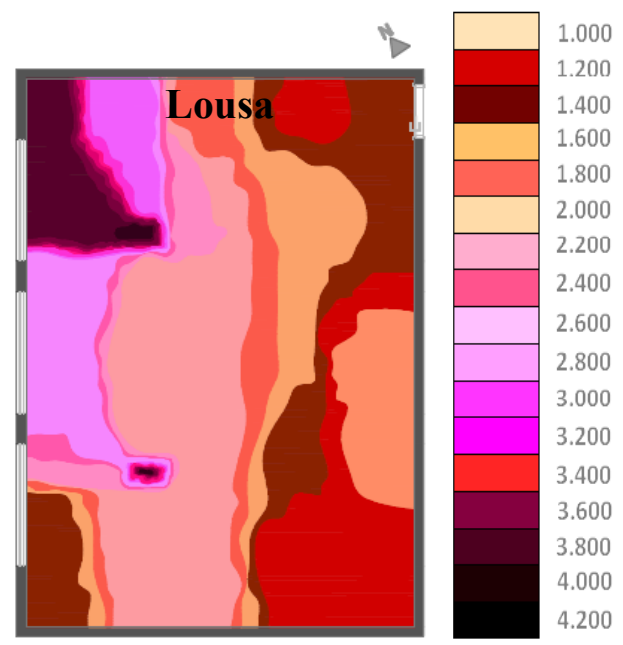

b.

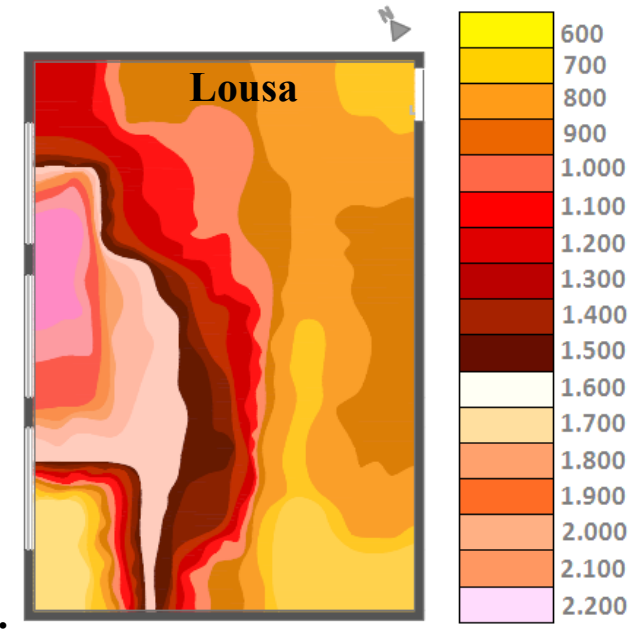

Fonte: Autores (2012)

Com a luz acesa no inverno, período da tarde, também foram coletados valores acima de 4.000 lux (Figura 10.a). Contudo no verão, na mesma sala, observou-se uma redução, que não excede 2.200 lux (Figura 10.b). Nas duas estações em todas as áreas os valores ultrapassaram o recomendado.

Figura 11 - Gráficos da Sala do $1^{\circ}$ Ano A, $1^{\circ}$ Ano B e $1^{\circ}$ Ano $\mathrm{F}$ durante o inverno (a.) e verão (b.) na condição de iluminação natural no período da tarde.

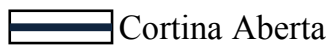

Cortina Fechada
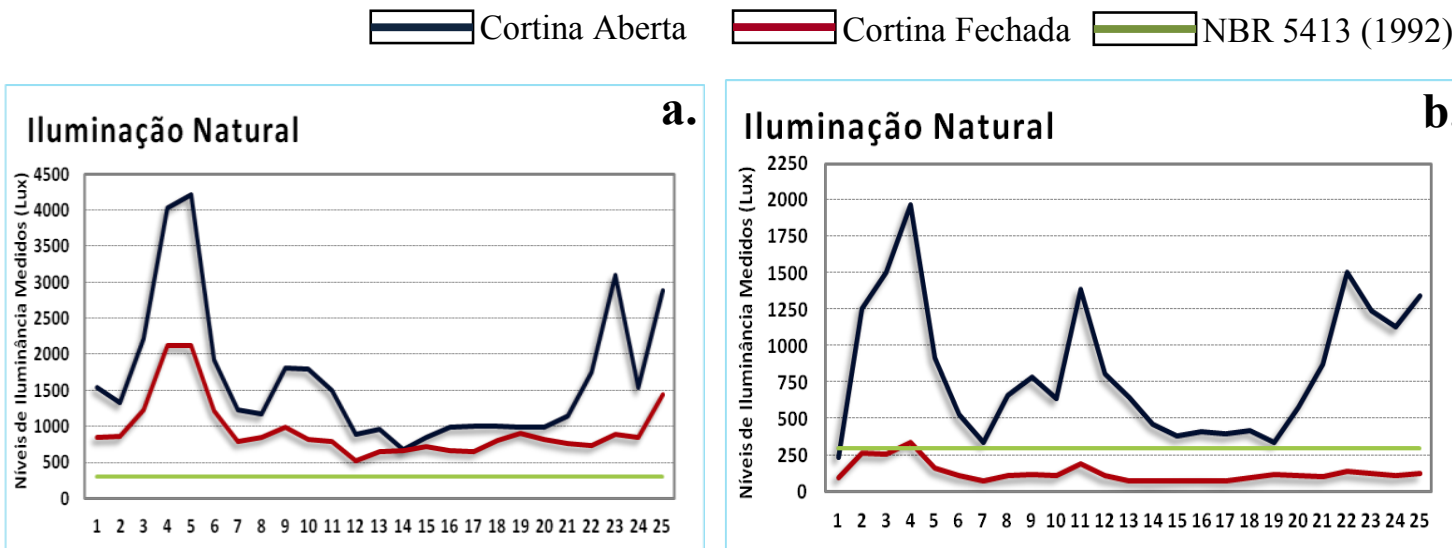

a.

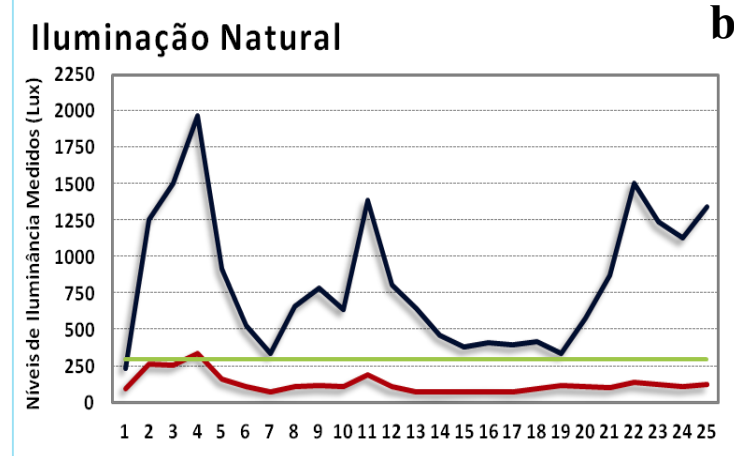

Fonte: Autores (2012) 
A maior média foi coletada durante o inverno (2.135,64 lux), de modo que a diferença entre as estações foi de 975,60 lux. Os valores no inverno, com a luz apagada, permaneceram, nas áreas próximas das aberturas, acima de 4.000 lux, enquanto no verão não ultrapassaram 2.000 lux (Figuras 11.a e 11.b). A medição de inverno apresentou maior média, 1.667,84 lux, sendo a diferença de 838,04 lux entre as estações.

\section{CONCLUSÕES}

O presente trabalho avaliou os níveis de iluminância em Álvares Machado - SP na Escola Municipal de Ensino Infantil e Fundamental e na Escola Estadual Profa. Angélica de Oliveira, coletando valores abaixo do recomendado pela ABNT NBR ISO/CIE 8995-1 (2013), sobretudo na condição de iluminação natural. A medição em cada sala também demonstrou que os níveis variaram no decorrer do dia e entre as estações, o que caracteriza a distribuição da iluminância natural e artificial como não homogênea, comprovando a dependência do sistema artificial nas áreas distantes das aberturas.

Os projetos de edificações escolares, conforme destacado no início, são um desafio devido ao processo de modificação do ensino. Assim, as pesquisas realizadas nas edificações construídas em décadas anteriores são subsídios para intervenções com objetivo de aprimorar, no caso da iluminação, o conforto lumínico de seus usuários, e podem servir de experiência para futuros projetos.

\section{AGRADECIMENTOS}

Os autores agradecem a Fundação de Amparo à Pesquisa do Estado de São Paulo (FAPESP) pelos recursos financeiros aplicados ao projeto no período de 2011 a 2013 (Processo $\mathrm{n}^{\mathrm{o}} 11 / 01037-0$ ), e pelo apoio na divulgação da pesquisa (Processo $\mathrm{n}^{\mathrm{o}}$ 2014/16362-1).

\section{REFERÊNCIAS}

ABNT - ASSOCIAÇÃO BRASILEIRA DE NORMAS TÉCNICAS. ABNT NBR ISO/CIE 8995-1: Iluminação de Ambientes de Trabalho - Parte 1: Interior. Rio de Janeiro. Rio de Janeiro, 2013. 46p.

KOWALTOWSKI, D. C. C. K.; LABAKI, L. C.; RUSCHEL, R. C.; BERTOLI, S. R.; PINA, S. A. M; CAMARGO, R. F.; BERNARDES, N. Melhorias do conforto ambiental em edificações escolares municipais de Campinas. In: ENCONTRO NACIONAL NO AMBIENTE CONSTRUÍDO, 5., 1999, Fortaleza. Anais... Fortaleza: ENCAC, 1999, p. 1-9. CD-ROM.

KOWALTOWSKI, D. C. C. K. Arquitetura escolar: o projeto do ambiente de ensino. São Paulo: Oficina de Textos, 2011. 272p.

KRÜGER, E.; ADRIAZOLA, M.; TAKEDA, N. Avaliação do desempenho térmico em escolas emergenciais da Região de Curitiba. In: ENCONTRO NACIONAL DE TECNOLOGIA DO AMBIENTE CONSTRUÍDO, 10., 2004, São Paulo. Anais... São Paulo: ANTAC, 2004, p. 1 14. CD-ROM.

PEREIRA, D. C. L.. Modelos físicos reduzidos: uma ferramenta para avaliação da iluminação natural. 245 f. Tese (Mestrado em Arquitetura) - Faculdade de Arquitetura e Urbanismo, Universidade de São Paulo, São Paulo, 2006.

VIANNA, N. S.; GONÇALVES, J. C. S. Iluminação e arquitetura. São Paulo: Geros, 2007. $376 \mathrm{p}$. 